\title{
New urban trends towards the use of public space in Turin
}

\author{
Sarah Isabella Chiodi \\ Politecnico di Torino, Italy \\ sarah.chiodi@polito.it
}

\begin{abstract}
What do we mean when we talk about public space? We asked this question, among others about the relationship between urban populations and public spaces, to some people in the context of the National Research Program (PRIN 2009) titled 'Public Spaces, moving populations and urban renewal programs'. This paper reports part of the outcome of the research done within the local unit of Turin (Italy), which has been developed with a set of interviews to local stakeholders and with a field research in the selected areas of the City Centre and the districts of San Salvario and Barriera di Milano. From the answers of the stakeholders emerged some relevant issues that I analysed through a selected literature about the concept of public space. The result is a sort of catalogue of typical public spaces of the city, as acknowledged by the local stakeholders and by the field research, and analysed through the international literature. The typologies identified are: traditional public spaces, 'cappuccino' spaces, weak sociality spaces, new virtual public spaces and the 'District Houses', a new type of public space emerging in the city. To identify them, some characteristic pictures of public spaces of Turin and interviews' pieces are also reported.

However, facing this scenario built on the empirical research, we should mind that the conflicting views of public space depend also on the professional and cultural background of the interviewees, which is such fickle data that it cannot be catalogued. So, the catalogue proposed is not exhaustive, but only indicative of the trend about new perspectives on the meaning of public space which emerged through research conducted in the city of Turin.
\end{abstract}

Keywords: public space; relational space; safety; weak sociality; district houses

\section{To cite this article:}

Chiodi, S. I. (2017). New urban trends towards the use of public space in Turin. The Journal of Public Space, 2(4), 77-90. DOI: 10.5204/jps.v2i4.I42

This article has been peer-reviewed and accepted for publication in The Journal of Public Space.

Please see the Editorial Policies under the 'About' section of the journal website for further information.

This work is licensed under a Creative Commons Attribution - Non Commercial 4.0 International License - https://creativecommons.org/licenses/by-nc/4.0/ 


\section{Introduction}

What do we mean when we talk about public space? We asked this question, among others about the relations between urban populations and public spaces, to some people in the context of the National Research Program (PRIN 2009) titled 'Public Spaces, moving populations and urban renewal programs', which involved seven different working groups located across different Italian universities.' This paper reports part of the outcome of the research done by the local unit of the Politecnico di Torino, which has been developed in the city of Turin with a set of interviews to local stakeholders and with field research in the selected areas of the City Centre and the districts of San Salvario and Barriera di Milano, as briefly described below.

From the answers of the stakeholders emerged some relevant issues that I analysed through the international literature about the concept of public space, which I used selectively to strengthen the different interviewees' orientations. The result is a sort of catalogue of typical public spaces of the city, as acknowledged by the local witnesses and observed by the field research. The typologies identified are: traditional public spaces, 'cappuccino' spaces, weak sociality spaces, new virtual public spaces and the 'District Houses', a new type of public space emerging in the city. To identify them, some characteristic pictures of public spaces of Turin and interview pieces are also reported. ${ }^{2}$ However, facing this scenario built on the empirical research, we should mind that the conflicting views of public space depend also on the professional and cultural background of the interviewees, which is such inconsistent data that it cannot be catalogued. So, the catalogue proposed is not exhaustive, but only indicative of the trends about the use of public space emerged from within the research, while the practice of public space, both in cultural and symbolic terms, remains in progress and difficult to distinguish from the sphere of private use (Mazzette, 20I3).

\section{Methodology}

The local unit of Turin worked using two main research tools, field observation and stakeholders' interviews, beyond literature review. While the field observation was performed independently by each research unit involved in the national research, the interviews were based on a shared questionnaire of 12 questions, of which just three were open answer. The aim of the questionnaire was to define which idea of public space the stakeholders had, which were the most relevant public spaces in the city in their opinion and which were their main social characteristics (if they are popular, their users, the activities developed there, the kind of social relations that usually happened there, their symbolic identity, the main issues involved within these spaces, the role of the public administration in shaping these spaces, etc.).

Twenty-eight interviews were conducted, and interviewees were selected based on two main criteria: the territorial reference of each (to which geographical area they referred -

\footnotetext{
I The research was coordinated by the prof. A. Mazzette, Università degli Studi di Sassari. The others research groups were: Politecnico di Torino - Local Scientific Manager, prof. A. Mela; Università degli Studi di Bologna - Local Scientific Manager: prof. M. Castrignanò; Università degli Studi di Milano-Bicocca - Local Scientific Manager: prof. F. Zajczyk; Università degli Studi di Genova - Local Scientific Manager: prof. A. Gazzola; Università degli Studi di Perugia - Local Scientific Manager: prof. R. Segatori; Politecnico di Bari Scientific Manager: prof. L. Bozzo.

${ }^{2}$ The interview pieces are translated in English by the author from the original transcription of the records, which were in Italian.
} 
among the three described below) and the job activity or the role they have within the specific area of the city (e.g. representatives of associations, traders, representatives of foreign communities, schools and social workers, politicians and administrators etc.). Moreover, we tried to keep an adequate gender mix and a certain age variety among the interviewees, but we cannot measure any relevant statistic factor because it was a qualitative survey.

The field observation was organized with a different grid in each one of the main areas selected. For example, while in the district of San Salvario, it was important to distinguish the use of public spaces in different sub-areas and in different seasons (notably the park in the warm/cold season), in the City Centre, it was more significant to observe diverse uses in weekdays and holidays or during the day and the night. So, just after almost one year, we managed to get a quite exhaustive analysis of the use of public spaces within each area. Finally, each member of the research unit developed and improved his own literature review on the topic of public space, depending on his personal scientific background - the research group included architects, planners, sociologist etc. - and their specific research interest (urban design, gentrification processes, immigration phenomena etc.) to enhance personal consideration, later gathered in a collective book. ${ }^{3}$ Notably, in this paper the literature has been adopted to analyse the definitions of public space quoted by the local interviewees and to organize a sort of catalogue of typical public spaces acknowledge by the research developed in city of Turin.

\section{Geographical context of the research}

Beside the set of interviews of local stakeholders as described above, the work done by the local unit of Turin ${ }^{4}$ involved field research in the selected areas of the City Centre and the districts of San Salvario and Barriera di Milano, which were chosen for the high variety of their users and the rich assortment of typologies of public spaces.

The City Centre is composed of plenty of traditional squares and buildings, representative of the history of the city and highly visited by tourists (such as Piazza Vittorio and the Murazzi, Piazza Castello, the Egyptian Museum, and the Mole Antonelliana or Museum of Cinema) and is characterized by high-quality architecture and good level of maintenance; but it has not always been like that. In the past, the Centre was marked by high physical and social degradation. Considerable urban interventions started in the early 90 s and improved up to 2006 (during the Winter Olympics). These updates have regenerated neighbourhoods and refurbished public spaces, in particular by making several streets and squares pedestrian-only. These changes have radically influenced the uses of public space in the city, by creating new public spaces or allowing new unexpected uses of the existing ones.

San Salvario is a semi-central district with a typical residential character, historically originated by the Enlargement Plan of the Capital of the mid-nineteenth century and by the subsequent expansion of the city, on the trails of the military boulevards (completed between 1860 and 1870). The majority of the buildings were built as an income by the middle-class. In the district is the most important park of the city: the Valentino Park. Originally, it was part of the Valentino Castle, one of the residences of the Savoy family,

\footnotetext{
3 Mela A., eds. (20I4), La città con-divisa. Lo spazio pubblico a Torino, Franco Angeli, Milano.

4 The Local Research Group was formed by: A. Mela, R. Albano, S. Chiodi, G. Marra, S. Mazzucotelli Salice, R. Novascone, G. Tarditi.
} 
but currently, the Castle hosts the faculty of architecture. In the park there is also the socalled Medieval Village: actually, a neo-Gothic settlement, built as a pavilion for the Italian General Artistic and Industrial Exposition, which took place in Turin in 1884; now it is an open-air museum. The neighbourhood and the park are two worlds partially separated, not only because of their morphology, but also because of their users, who rarely coincide. The park attracts sportsmen, school groups and tourists (especially in the neomedieval village), who do not typically visit the neighbourhood. On the other hand, many users of the neighbourhood, especially shopkeepers and night-clubbers, almost never go to the park, with the only exception being during the summer, when some nightclubs are located in the open park. San Salvario is also changed from the past, but not because of a renewal program led by the city administration as it is occurred in City Centre; here the change occurred gradually and mostly from 'the bottom', as a process of local development close to gentrification, which made it a kind of fashion district. Now there are more youths here, some immigrants moved out and new Italian families moved in.

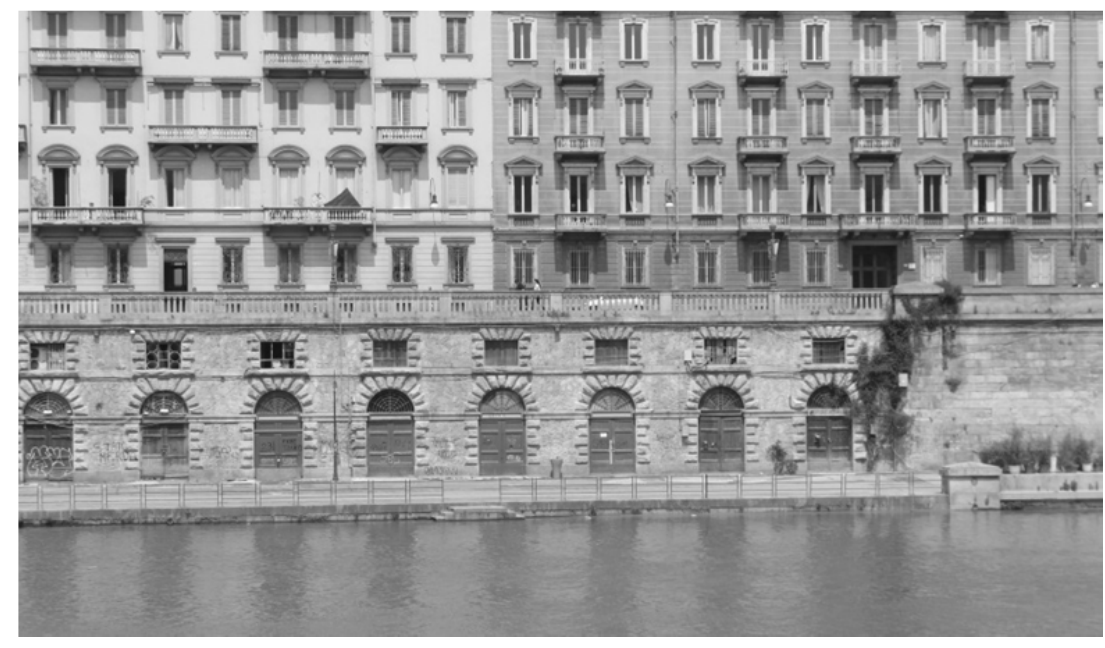

Fig. 2 - The arcades of "Murazzi”.

The district of Barriera di Milano, which literally means 'barrier of Milan', because there actually used to be a custom barrier to Milan, is the most segregated among the three observed by the field research. In this context, segregated does not mean geographically separated in the suburbs (consider that it is adjoined to the old Roman City, the oldest historic centre of Turin), but it means socio-culturally and historically isolated. It is considered a social periphery and historically it was born like these; actually, it was a new district built for the industries and their workers. Today, the old industries are not working anymore, and the working-class population (mostly made of immigrants from southern Italy) who was predominating in the past, have been partially substituted by new immigrants from other counties (mostly North Africa, China, Eastern Europe). This change occurred also because of the proximity of the market of Porta Palazzo, which represents one of the most well-known reference points for the majority of foreign immigrants in search of work, because it represents the place where they can get help from their fellow countrymen. Recently, to contrast this segregation, an urban regeneration project called Urban Barriera ${ }^{5}$ has been taking place there, by following the

${ }^{5}$ The project is started in $201 \mathrm{I}$ and ended in December 2015. http://www.comune.torino.it/urbanbarrieral 
European bottom-up approach which characterized the regional urban cohesion policy (European Commission, 2003), with the collaboration and the proactive interaction among all the actors and beneficiaries involved in the project (Public Administration Sectors, local activities or associations, Institutions, citizens, local business etc.). So, some small changes are taking place by intervening both on the physical space and on the socioeconomic one.

\section{A catalogue of typical public spaces}

Weak public spaces

The idea of 'weak' sociality contrasts with the idea of a 'strong' one, as suggested by Crosta (1996) and with an implicit reference to the famous distinction ${ }^{6}$ of the sociologist Marc Granovetter (1973) between strong and weak bonds. But in this context, 'weak interaction' is meant as a codified and common action imposed, for example, by a commercial business or an organised event, and it simply envisages spending time together among other people without any personal implication. On the other hand, a 'strong interaction' is supposed to take place between people sharing mutual and reciprocal relations or a common goal, with personal or intimate implications. This idea arises from the most frequent definition of public space given by the stakeholders. Indeed, almost none of the people interviewed, apart from one, ${ }^{7}$ referred to a 'strong' vision of sociality or made specific mention of shared civic values. Public space is considered by most as a meeting place for leisure time, sports and entertainment. As they stated:

"Basically, public space means being able to spend time on the streets, occupying and passing time in a square, sitting on a bench, in a green area, in a place where you can take a break."

"Public space [is a] space open to meetings with others, for shared use, where you observe people and are observed by people, where you simply are with others."

"... [public space] is used to create sociality: [it is the place] where it is possible to have the most contact with others, people outside of our usual sphere."

"The main function [of public space] is to bring people together ... so they can talk to each other"

“...there aren't many relations, there are people in public spaces, but it doesn't mean that there are relationships between them. Actually, among adults there aren't many deep relationships. Occasional interactions happen by chance."

Public spaces are often identified with the most traditional open space within a city

\footnotetext{
6 The author distinguishes strong and weak bonds in the context of social networks of individuals, by highlighting the economic value of the weak links (links without particular affective relationships, such as those between shop owners and customers, or between two colleagues etc.) as a potential work resource. However, here this distinction doesn't imply any judgment about the value of the two types of interaction and there is no reference to economic sociology.

7 Here I report the piece of the interview: [Public space] offers people the chance to frequent it in their free time, doing things that increase their awareness as citizens. Space has to stimulate a sense of belonging and of citizenship.
} 
(squares, parks etc.), but the idea of sociality that appears behind the claims does not imply deep relationships, and it is limited to a 'weak' idea of spending time together: people crowding public spaces, without developing any civic culture or political stance, as it was is the past ${ }^{8}$, when 'big squares were vital to every city, because there public life was developed, while now is relegated indoors' (Sitte, 1889).

\section{"I consider public spaces as spaces for transit." \\ “...public spaces [are] spaces for transit where people pass and use the space, but they are not necessary living there."}

"Public space is for leisure time, going for walks, having fun and sport."

"It is a place where $[\ldots]$ we can get together and let off steam."

The interpretation of public space, as 'weak' or a secondary place of civic culture, revokes numerous studies about the role of public space in cities.

The traditional literature on urban studies, from Simmel, Mumford and Jacobs, up to the contemporaries, Sennet, Sandercock and Zukin, sustains that there is a strong link between public space and civic culture. Public space is usually understood as privileged space to develop civic virtues and public opinions. In particular, these spaces are typically characterised by heterogeneity and unpredictability, as J. Jacobs (1960) affirmed; the same distinctive characteristics that now S. Zukin (1995) considers vanished in the contemporary city (the reference is New York).

Today, two important elements break this link up: the change of the characteristics of public space itself and the fragmentation of the public sphere. Not only is the public sphere changed, but it no longer has the characteristics required for political participation and civic formation. And in fact, the sociality among people in the public space can't be considered the main vehicle for political participation and for building citizenship up. The elements of diversity, complexity and disorder, which were at the centre of public life up until the $18^{\text {th }}$ century, now have been cancelled by the dominion of the private and intimate sphere over the public sphere (Sennet, 1982). Furthermore, this phenomenon opens up a process of privatisation, securitisation and standardisation of public space. The contemporary city is destroying common values little by little, and the urban space is progressively homologated and just a place for commerce and leisure (Secchi, 2000). The open relational space that characterised the public space in the past, now is blinded in spaces where relations are mainly commercial and business. Notably, someone said:

“...the main activity [of public space] is entertainment and shopping and restaurants."

In particular, Piazza Vittorio (which was recognised as one of the most important public spaces in the city) is considered by many people as a nightclubbing space or as a setting for organised events (exhibitions, commercial events, commercial fairs etc.):

"...there are regularly events or other organised activities with music, or the chocolate fair CioccolaTO, to a wide variety of other exhibition. We could say, it almost an exhibition area more than a civic space."

${ }^{8}$ The reference period is much before the XIX century, when the authors is writing. 
However, neither Piazza Vittorio or other public spaces in the city have ever been nominated as spaces for political aggregation or where developing a civic culture. Particularly, some people, missing the past, spoke about the value of public space: "I came here almost thirty years ago [...], then the heritage commercialised the [public] spaces in order to create a type of nightclubbing that I don't like. Before, people that came here were of different origins and colours but they all had similar ideals, in terms of idiom and politically too, $[\ldots]$ they were socially committed people. The word 'public' itself means that the space should be available for people and not just for drinking stupid cocktails."

Therefore, public space is changed by the virtue of a different quality of social rations that happen there and because it is no longer a strong catalyser of civic and political culture, but it is changed also because sociality in public space does not represent anymore the only (and for someone also the sufficient) sphere of civic and political formation. Indeed, as asserted by Amin (2008), sociality in public space is not sufficient to affirm the civic and political sphere and it would be 'heroic' to admit that more vibrant and inclusive public spaces can increase urban democracy. This does not mean that the bond between public and political space is denied nowadays, but, that this bond is become very weak due to the fact that public culture does not circulate exclusively in squares, but it is spread across other numerous environments, not strictly urban, and notably through the new media. Today, the spaces where people develop public opinions are talk shows, radio programmes, newspapers, social networks and Internet in general, while rarely are political meetings in squares or conversations about collective problems happening in the streets.

Weak sociality does not mean poor environment, even if no deep interactions happen there. Indeed, in the opinion of the interviewees, to fulfil its function properly, a public space needs some fundamental features. It should be open, safe and friendly; where open is understood with a social meaning and not physically. So, it should be accessible and not elitist, without strict and formal behavioural rules. Furthermore, facilities and design are important.

"...areas where people can sit, communicate and spend time in nice environment" Moreover, the appeal of a public place has been considered another important feature, because it allows to define its identity and it makes the popular. The appeal has been understood as a catalysing element, one which can be various: it can be a museum or an historical architecture or a monument, as it is common in the City Centre (e.g. the Egyptian museum, Piazza Castello etc.), or it can be the presence of any leisure facility.

"... a space with an appeal ... it can be amazing historical complex, or it can be an attraction of social nature. I'm thinking about Piazza Vittorio, for example, with all its venues, a very attractive space; or other areas, such as the district of San Salvario, which have no immediate historical connotations, like Piazza Castello, but it become attractive due to the presence of venues, cafés, restaurants etc..."

\section{Cappuccino spaces}

Some people consider the presence of places for eating and drinking as fundamental within a public space, partially contradicting the idea of a public space previously identified, which would be open (socially), friendly and truly accessible to everybody. 
"Public space is a space where you find a certain type of layout, bars, shops."

"[Public space] is a natural area of passage, because it is very commercial, it has shops." "an attractive place where people can also go shopping or can eat."

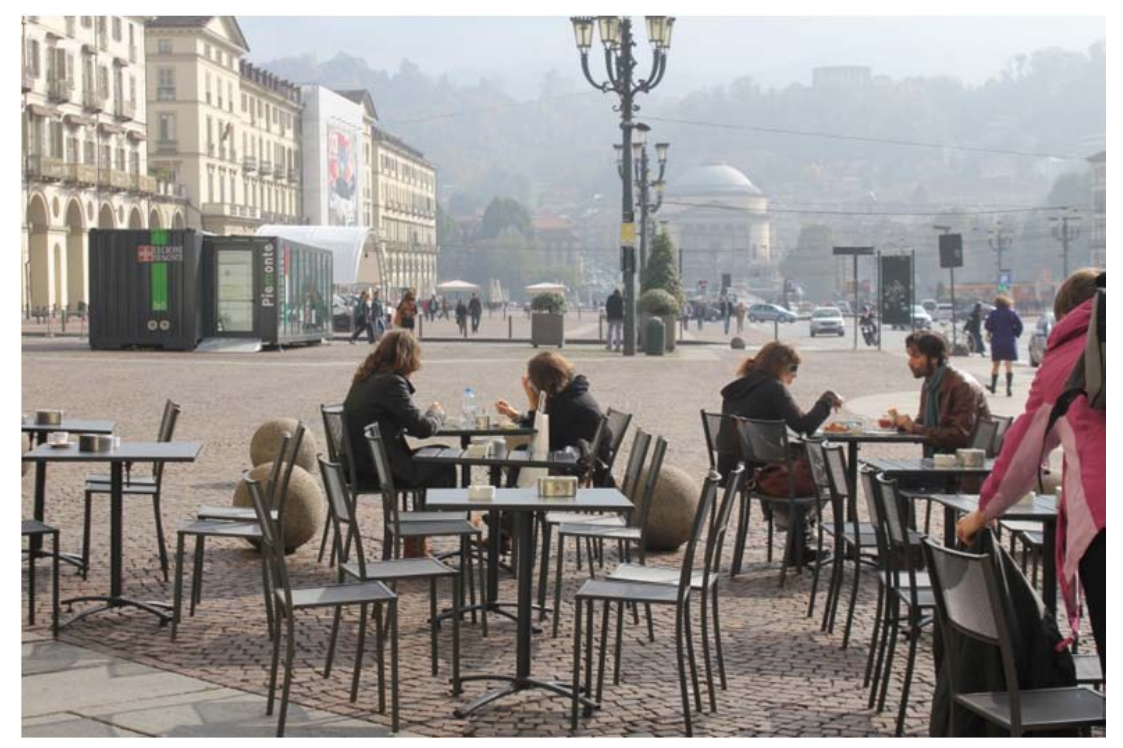

Fig. 2. A view of a "public" space in Piazza Vittorio.

The commercial image of public space originating from the interviews' pieces reflects the aesthetic American model of public spaces described by S. Zukin (1998). According to it, commercial spaces - shops, restaurants, cafés, which are always private - are considered as 'public' spaces, while roads and car parks - which are generally public - are designed as 'private' spaces. It is a model based on shops, entertainment spaces, fashion museums etc., which shape a city built on the consumption of mass products from globalised brands (such as Starbucks Coffee). S. Zukin (1995) exemplifies this model describing the revitalisation project of Bryant Park, New York. The theoretical aim to 'civilise' the park has been achieved by expanding the consumption offer (bars where you can drink a 'Cappuccino' - the Italian word is used by the author herself) and the users' behaviour has been influenced by very good levels of maintenance of the spaces and by a high surveillance with security guards.

Nowadays, some American shopping malls try to mitigate the artificial appearance of these new 'public' spaces by making people feel the environment is 'more natural' with the presence of (Mood) ${ }^{9}$ music and pervasive smells. But, actually, the true aim of this choice is to increase sales: making the space more comfortable increases the probability that people buy products.

Despite some interviewees underlining the role of consumption in public spaces, the process of high regulation and privatisation of public spaces described by $\mathrm{S}$. Zukin does not truly appear in their claims. However, this process of 'domestication by Cappuccino' seems to be a serious perspective of transformation of public spaces in the next future. Indeed, the high space commercialisation can bring very restrictive measures in the use of

\footnotetext{
${ }^{9}$ The term Mood is used to identify the gentle and relaxing new music introduced into some shopping malls, airports, lifts etc as a background sound in order to replace the more stressing Muzak style (derived from Muzak Holding, which has now been overtaken by Mood Media, the international sensorial marketing company).
} 
'public' space, with the risk of codifying every kind of behaviour. As asserted by F. La Cecla (2000, p. I35) 10 'at international level, town planning became a sort of safety tutor, an urban safety guaranteed by a strict social division (gated communities are an example, along with gentrification theories and urban renewal - as a response to the contemporary multi-ethnic immigration) [...]. As if public space was a huge shopping centre, many uses should be required there: sitting, spending time or wasting time. Public places are not living places, but places to consume according to the authority's rules'.

The dilemma is between what is artifice and reality, between Starbucks Coffee, a symbol of globalisation, and the nature, which means the real city in contrast with the glossy one, made of shop windows and enclaves. It is no mere coincidence that shopping malls, the 'non-places' (Augè, 1993) at excellence, are changing into relational spaces, the new 'public' spaces, full of attractions and people, and often more people than on the urban streets. Notably, the concerts in Turin are often held in the shopping mall 'Le Gru' (where there is an important summer rock music festival every year), and increasingly less in public squares.

Therefore, if we define 'public' as the space that joins together people, perhaps we should consider the concept of public space on a broader basis, by admitting that hybrid relational spaces, which are no longer just squares and streets, are increasing. If we look closer at this phenomenon of privatization of public spaces, we see that, on one hand, consumer spaces are expanding on streets and in the squares (although there are no global cafés in Turin), while on the other, shopping malls and outlets are shaping like traditional public spaces, with small internal streets and squares decorated with fountains and monuments. But the main risk is the loss of the sense of reality, by being absorbed in alienating environments and emotions. It means a sort of 'gentle totalitarianism', where people are victim of an illusion of intimacy, losing the real space and time, which actually are much harder to face than these abstractions. (Augé, 2013).

\section{New virtual public spaces}

New communication and information technologies have very much influenced the use of public (and private) space. As already asserted by J. Gehl in 199I, telephone, television, personal computers and more (but nowadays we can add social networks, blogs and Internet in general) have introduced new behavioural models and lifestyles. Direct meetings in public spaces can be replaced by indirect and remote relations. Furthermore, the facility of modern transports (such as cars diffusion, extensive urban and suburban public transport networks, high-speed trains etc.) has made it possible to live and work far away, with the consequence of losing the everyday meetings that used to happen within the neighbourhood of residence. According to this change, some interviewees commented:

“for me, public spaces are still places [...]. I don't mean that people don't meet on social networks, but I don't see them as a public spaces. [...] public spaces in my opinion are [those where] people meet in a yard, in a museum, in tangible places."

Despite the fact that the previous statement says that virtual spaces do not represent a real public space; however, the development of communication and information

\footnotetext{
${ }^{10}$ The original text is in Italian, the translation here is proposed by the author of the paper.
} 
technologies is not completely a negative issue. We should consider that new virtual public spaces, definitely, did not break up social ties and reduce real meetings between people in material public spaces, but they have allowed the formation of new networks and alternative manifestations of civic culture, by accelerating and intensifying the dissemination of information and communications and by creating new actual public spaces, where people can develop their civic and political culture. Therefore, nowadays we can consider material public space, as it was traditionally considered, as just one of the areas to develop civic culture and political participation, and it is probably one of secondary importance (Amin, 2008).

\section{The Neighbourhood Houses}

A particular type of public space has recently been developed in the city of Turin, offering an innovative reinterpretation of some characteristics of traditional public space. We analyse it within the research through the observation and the stakeholders' interviews; notably we spoke with some of the managers of these innovative public spaces. It is the so called 'Neighbourhood House' (the name comes from a sort of market strategy chosen by the municipality): buildings fallen into disuse (like public bathrooms), often owned by the municipal administration, and restored for social uses with public and private funding, and with the collaboration of the third sector, businesses and citizens. The building itself usually has closed and open spaces, like yards or small gardens. They host various activities of collective interest (rehearsal rooms for musicians and theatre companies, coworking spaces, rooms to hold classes and meetings, entertainment activities, after-school clubs, conferences and public presentations, film show, concerts and parties etc.) and they are equipped with restaurants or cafés. The houses are managed by associations, local development agencies or foundations and they receive the support of public and private organisations because they are unable to generate economic resources enough to support themselves.

This typology includes several spaces in Turin: 'la Casa del quartiere di via Morgari' (literally 'the neighbourhood house of Morgari street') in the district of San Salvario, the (ex) 'Public Baths' in the district of Barriera di Milano and other spaces in different districts of the city which we did not observe directly: 'Cascina Roccafranca' (in the district of Mirafiori Nord), the 'House in the Park' (Colonnetti Park, Mirafiori Sud), the 'Cecchi Point' (Aurora district), the '+ Space Four' (San Donato district) and 'Barrito' (Nizza Millefonti district). All these spaces have been opened within the last ten years.

The Neighbourhood House of San Salvario, in particular, is one of the spaces we observed closely. It is located in the former public baths of the district, like one of the other spaces mentioned. Like a real house, it does not offer services, but hosts people and associations with their own cultural activities. More than 60 associations and about 100 groups perform their cultural, but also recreational and support activities there. For example, there is a self-managed play area for children, classes of Arabic language and music are held by local associations, and there are repair shops etc. The role of this space has become very important in the district, both because it makes its spaces available for meetings or other cultural activities open to the public, but also because its presence has partly conditioned the opposite public space: a little square called 'Piazzetta Donatello', where the Church of the Sacro Cuore di Maria" is also located. As stated in an interview "The curch of the Sacro Cuore di Maria was designed by Carlo Ceppi, exponent of the eclectic taste of
the second half of the $19^{\text {th }}$ century, pupil of Carlo Promis. He was also the creator (with Alessandro 
(referring to the 'Casa del quartiere di via Morgari'):

"...in the years when this building was abandoned, the square (in front of) was less frequented, it had it was a place where for homeless and drug dealers [...] The presence of the 'Casa del Quartiere' (and of other new bars which opened next to it), has made the inhabitants of the district (including the elderly) more familiar with this space. Now it is populated by old men and women, mostly Italian, and by some youngsters and students who attend the 'Casa del Quartiere', sometimes also by foreigners; they seat on the benches using their computers, because there's a free wi-fi connection."

These houses, like the more traditional public spaces, are spaces of civic formation and for strengthening the public sphere, re-proposing the cultural value of public space. Moreover, these spaces are modern because they communicate online within the virtual space. All the neighbourhood houses mentioned are joined in a network ${ }^{12}$ which highlights their similarities and formalises the birth of this new type of public space.

The innovation brought by this particular type of public space is on two levels: one is organisational and economic, the other one is socio-cultural. On one hand, the houses are sustained by an innovative horizontal cooperation by all the stakeholders involved in their development, and by the integration of public and private funds. On the other, they reaffirm and renew the typical values of public space as a place of identity for the local community, for exchanging culture, of civic formation, but also as symbolic place, as urban square, as central civic centres recognised by the inhabitants.

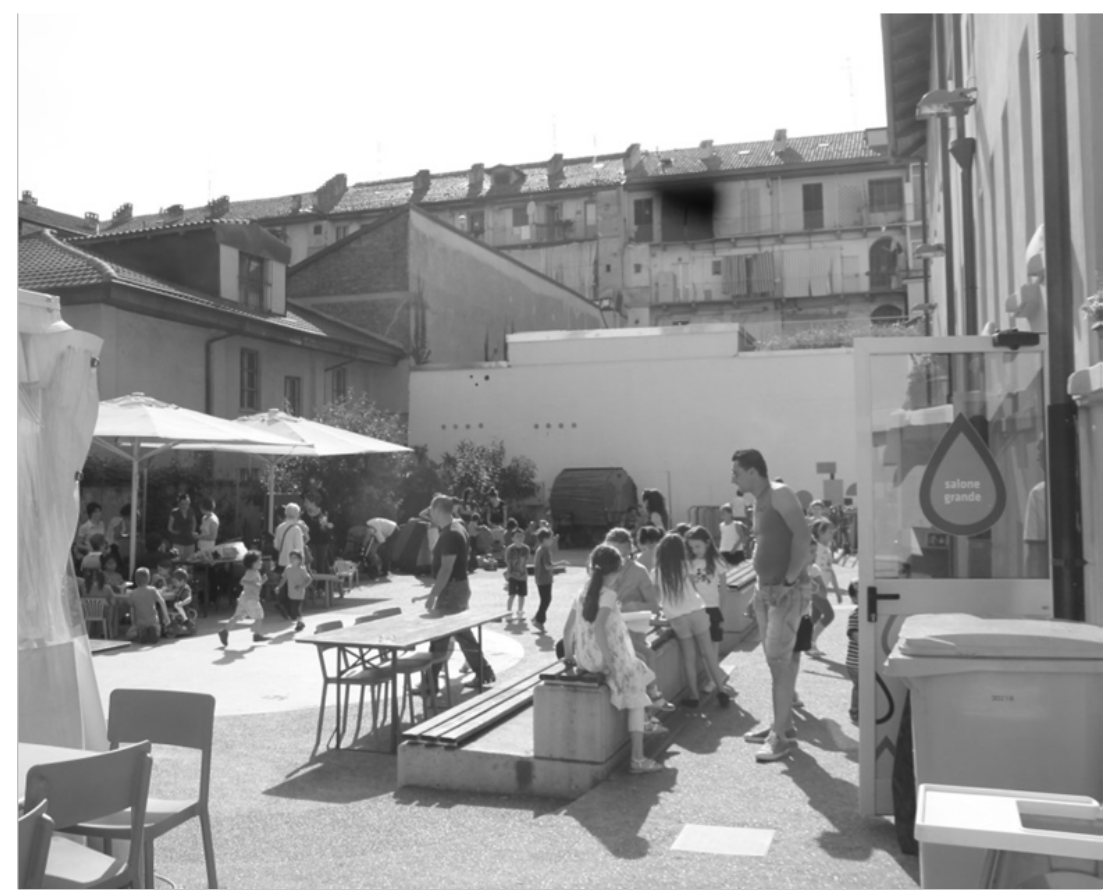

Fig. 3. A summer party in the yard of the "Casa del quartiere" of San Salvario

Mazzucchelli), of Porta Nuova railway station.

12 http://casedelquartiere.wordpress.com 


\section{Concluding comment}

This article has argued a list of different typologies of public spaces occurring in the city of Turin and notably in some districts the city, as described in paragraph number three. The typologies suggested are gathered through the empirical work of the nucleus of the Politecnico di Torino within a research of national interest developed in different Italian universities simultaneously, by following the methodology illustrated in the second paragraph (distinctly with stakeholders' interviews and the observation). In order to better explain the typologies, statements of the interlocutors have been reported and some references from the literature have been employed.

The article, through the typology of 'weak public spaces', has outlined that nowadays the traditional idea of public space has no longer a direct connection with the formation of civic culture and that it represents a space of a weak sociality. In general, it has been witnessed the impoverishment of the traditional idea of public spaces, which have lost their civic and social initiation value, also because of the incoming consumer culture that has produced new different artificial spaces, the ones have been defined 'cappuccino spaces'. Moreover, 'new virtual public spaces' are spreading in our everyday life, partially acquiring the lost role of traditional public spaces, by affirming a new civic culture grew up with talk shows and social media. Furthermore, the typology of 'neighbourhood houses' represents a new understanding of the traditional concept of square and cultural or literary café.

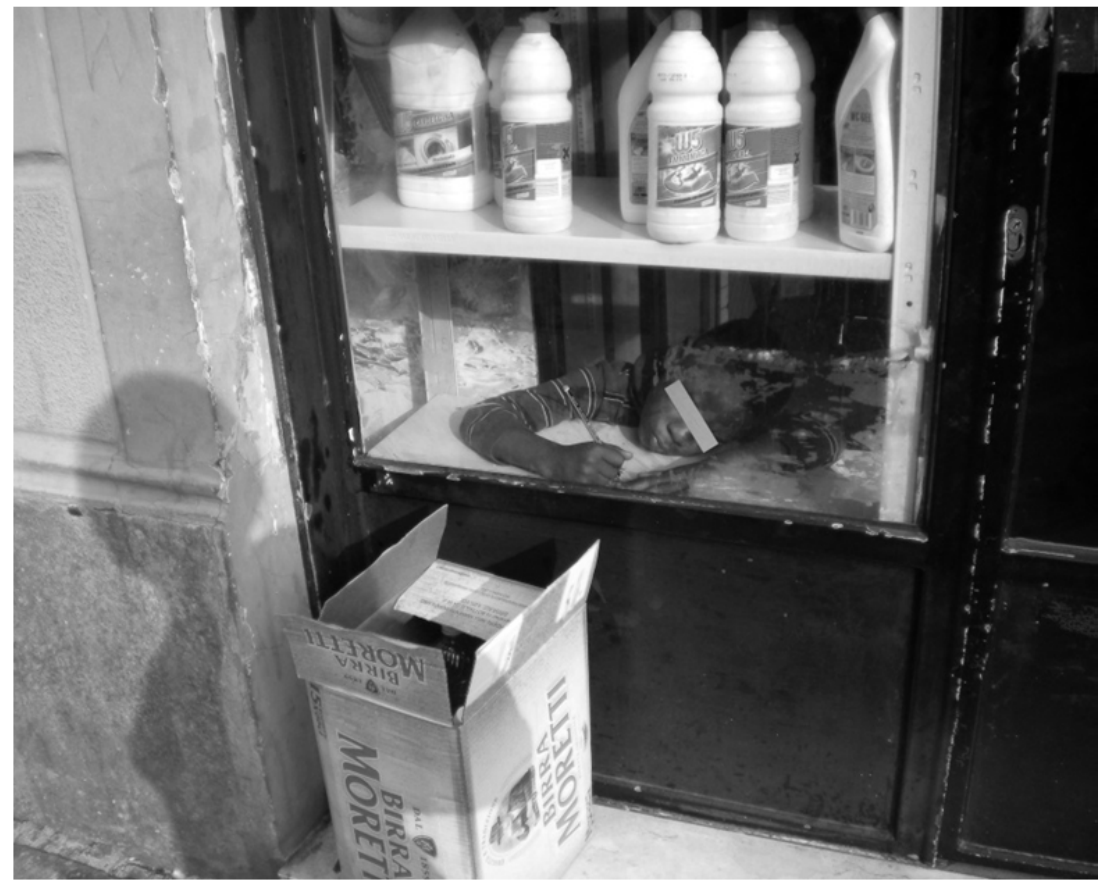

Fig. 4. A view to a public space...not for everyone.

Finally, we should consider an important limit regarding the definitions of public space given by the stakeholders: the subjective point of view of all them, which makes it difficult to generalize their opinions as exhaustive definitions of public space. Their opinions have been always given by regarding their personal experience, their work, their life experience. The spaces mentioned are squares, streets, parks, outdoor venues, but 
everyone sees them through their own eyes. Some people identify streets as advertising space, because they have a commercial business, but for others the same places are considered as jogging areas, because they are interested in sports. The limit is that very few describe the concept of public space as something that belongs to everyone, indeed, underlying its public value, but they keep their personal opinion. For example, for those who work in the commercial sector, public space is a place to do business and to get new customers:

"... in my opinion, public space is where there are lots of passers-by, where you can advertise [...] there you can take a percentage for the people that pass through the area. $[\ldots]$ these are the most visible spaces."

While, for people who work in the tourism sector, public space is a place that attracts visitors, for its architectural and historic value, where is important to have also the opportunity to do shopping and to get some entertainment.

"It is a space that also has interesting architectural characteristics, so it becomes a space for cultural aggregation, but also a space for social aggregation [which attracts visitors] due to the presence of venues, coffees and restaurants."

The youngest identify public space as a place where they can have fun: nightspots or local meeting places, to move on to other entertainment venues. The immigrants, depending on the characteristics of their culture, identify different values of public space, from recognizing in it a sort of extension of their home (as a lounge or a bathroom), up to denying the idea of public space (is the case of the local Chinese community, which live conviviality in the closed and private space of their working environment).

Therefore, we can conclude, almost with an oxymoron, that there is nothing more private than public space.

\section{Notes}

All the pictures used in this article were taken directly by the author during the research.

\section{References}

Amin, A. (2008). "Collective culture and urban public space”, in City, vol. 12, n. I: 5-24.

Augè, M. (1993). Non luoghi, Milano: Elèutera. (Original work: 1992, Non-lieux, Paris: Seuil).

Augè, M. (20I3). Interview by C. Magnanimi, in D by La Repubblica, 9 march 20I3: II6.

Crosta, P. L. (1996). "Connecting knowledge with action in the interactive porcess of planning: what knowledge is relevant and with whose actions are we connected?" in Planning Theory, 16.

European Commission (2003). II partenariato con le città. L'Iniziativa comunitaria URBAN (Italian version), Printed in Begium.

Gehl, J. (199I). Vita in città. Spazio urbano e vita sociale, Roma: Maggioli. (Original work: 1980, Livet mellem husen, Copenhagen: Arkitektens Forlag).

Granovetter M. (1998). "La forza dei legami deboli", in Id., La forza dei legami deboli e altri saggi, Napoli: Liguori, p. II5-I46) (Original work: 1973, "The Strength of Weak Ties", in American Journal of Sociology, 78: I360-1380). 
Jacobs, J. (196I). The Death and Life of Great American Cities, New York, NY: Random House.

La Cecla F. (2000). Perdersi. L'uomo senza ambiente, Roma-Bari: Laterza.

Mazzette, A. (2013). "Città tra privato e pubblico", in Id. (ed.), Pratiche sociale di città pubblica, RomaBari: Editori Laterza.

Secchi B. (2000). Prima lezione di urbanistica, Roma-Bari: Laterza.

Sennet R. (1982). II declino dell'uomo pubblico: la società intimista, Milano: Feltrinelli. (Original work published 1977: The fall of public man, New York: Knopf).

Sitte C. (1996). L'arte di costruire le città, Jaca Book: Milano. (Original work published I889, Der Stadte-Bau nach seinen Kunstlerschen Grundsatzen, Wien).

Zukin S. (1995). The Cultures of Cities, Oxford: Blackwell.

Zukin S. (1998). "Politics and aesthetics of public space: the 'American model' ", Published in Ciutat real, ciutat ideal. Significat i funció a l'espai urbà modern [Real city, ideal city. Signification and function in modern space]. Barcelona: Centre de Cultura Contemporània de Barcelona, 1998 (Urbanitats; 7). 